\title{
Rising infant mortality rates in England and Wales-we need to understand gestation specific mortality
}

\author{
Peter J Davis consultant paediatric intensivist ${ }^{1}$, Alan C Fenton consultant neonatal paediatrician ${ }^{2}$, \\ Christopher J Stutchfield specialist registrar ${ }^{1}$, Elizabeth S Draper professor of perinatal and paediatric \\ epidemiology ${ }^{3}$
}

${ }^{1}$ Paediatric Intensive Care Unit, Bristol Royal Hospital for Children, Bristol BS2 8BJ, UK; ${ }^{2}$ Newcastle Neonatal Service, Royal Victoria Infirmary, Newcastle upon Tyne NE1 4LP, UK; ${ }^{3}$ Department of Health Sciences, University of Leicester, Centre for Medicine, Leicester LE1 7RH, UK

The $B M J$ has covered the many legitimate concerns regarding the state of child health in the United Kingdom, ${ }^{12}$ but the reported rise in infant mortality rates from 2015 onwards $^{3}$ requires a more detailed analysis before being included in this overall picture.

Infant mortality rates are calculated by combining neonatal $(0$ to 28 days) and postneonatal (4 weeks to 1 year) mortality rates. The latest figures for England and Wales from the Office for National Statistics show that postneonatal mortality rates fell consistently over 30 years to 2016 . Neonatal rates decreased until 2014 before rising again. But this increase relates solely to additional deaths reported in the first day of life, which is probably secondary to more "live births" being included at, or even below, the extremes of viability. Although survival among babies born at 22 and 23 weeks' gestation is no longer exceptional, ${ }^{4}$ mortality remains high. The number of live born infants at less than 23 weeks' gestation, however, has increased considerably over three years (376 in 2014; 427 in 2015; 545 in 2016), ${ }^{5}$ affecting overall infant mortality rates.

The increasing number of live births below 23 weeks' gestation may relate to changes in neonatal practice, such as babies now being observed for signs of life before decisions regarding ongoing care are made, or to changes in reporting, after recent coroners' directives that any baby born with a detectable heartbeat should be considered a live birth, whatever the gestation.

Concerns over differences in registration practices around extremely preterm birth limit the use of these data. The Europeristat group have said that routine data should exclude those born at less than 24 weeks' gestation. ${ }^{6}$ Since 2013,
MBRRACE-UK has provided such data for all UK countries using these exclusions. ${ }^{478}$ Gestation specific mortality rates would enable more informed and accurate monitoring of mortality rates over time and, if accepted internationally, better direct comparisons of healthcare systems.

\section{Competing interests: None declared.}

Full response at: https://www.bmj.com/content/360/bmj.k1270/rr.

1 Wise J. Child health crisis: calls for urgent action must not go unheeded. $B M J$ 2018;360:k1270. 10.1136/bmj.k1270 29559441

2 Viner RM. NHS must prioritise health of children and young people. BMJ 2018;360:k1116. 10.1136/bmj.k1116 29540344

3 Office for National Statistics. Infant mortality rates increase in England and Wales in 2016. https://www.ons.gov.uk/peoplepopulationandcommunity/birthsdeathsandmarriages/deaths/ bulletins/childhoodinfantandperinatalmortalityinenglandandwales/2016\#infant-mortalityrates-increase-in-england-and-wales-in-2016.

4 Manktelow BN, Smith LK, Prunet C, Smith PW, Boby T, Hyman-Taylor P, Kurinczuk JJ, Field DJ, Draper ESMBRRACE-UK Collaboration. Perinatal mortality surveillance report, UK. Perinatal deaths for births from January to December 2015. The Infant Mortality and Morbidity Group, Department of Health Sciences, University of Leicester, 2017.

5 Office for National Statistics. Birth characteristics. https://www.ons.gov.uk/ peoplepopulationandcommunity/birthsdeathsandmarriages/livebirths/datasets/ birthcharacteristicsinenglandandwales

6 Delnord M, Hindori-Mohangoo AD, Smith LK, etal. Euro-Peristat Scientific Committee. Variations in very preterm birth rates in 30 high-income countries: are valid international comparisons possible using routine data?BJOG 2017;124:785-94. 10.1111/1471-0528.14273 27613083

7 Manktelow BM, Smith LK, Evans TA, etal. MBRRACE-UK collaboration. Perinatal Mortality Surveillance Report UK Perinatal Deaths for births from January to December 2013. The Infant Mortality and Morbidity Group, Department of Health Sciences, University of Leicester, 2015.

8 Manktelow BN, Smith LK, Seaton SE, etal. MBRRACE-UK Collaboration. MBRRACE-UK Perinatal Mortality Surveillance Report, UK Perinatal Deaths for Births from January to December 2014. The Infant Mortality and Morbidity Studies, Department of Health Sciences, University of Leicester, 2016.

Published by the BMJ Publishing Group Limited. For permission to use (where not already granted under a licence) please go to http://group.bmj.com/group/rights-licensing/ permissions 